\title{
Presença de compostos de nitrogênio em águas de poços
}

The occurrence of nitrogen compounds in well water

\section{Janete Alaburda e Linda $\mathbf{N}$ ishihara}

Divisão de Bromatologia e Q uímica do Instituto Adolfo Lutz. São Paulo, SP - Brasil

ALABU RD A Janete, Presença de compostos de nitrogênio em águas de poços Rev. Saúde Pública, 32 (2): 160-5, 1998

(c) Copyright Faculdade de Saúde Pública da USP. Proibida a reprodução mesmo que parcial sem a devida autorização do Editor Cient́fico. Proibida a utilização de matérias para fins comerciais. All rights reserved. 


\title{
Presença de compostos de nitrogênio em águas de poços
}

\section{The occurrence of nitrogen compounds in well water}

\author{
Janete Alaburda e Linda Nishihara \\ Divisão de Bromatologia e Química do Instituto Adolfo Lutz. São Paulo, SP - Brasil
}

\begin{abstract}
Resumo
Introdução A presença de compostos de nitrogênio nos seus diferentes estados de oxidação é indicativo de contaminação do aquífero e de possíveis condições higiênicosanitárias insatisfatórias. O nitrito e o nitrato estão associados a dois efeitos adversos à saúde: a indução à metemoglobinemia e a formação potencial de nitrosaminas e nitrosamidas carcinogênicas. Assim, foi verificada a contaminação das águas subterrâneas por compostos de nitrogênio, através da determinação de nitrogênio amoniacal, nitrogênio albuminóide, nitrito e nitrato, e avaliada a adequação da legislação vigente.
\end{abstract}

Material e Método

Resultados

Conclusão
Foram analisadas 607 amostras de águas de poços localizadas predominantemente na Região Metropolitana da Grande São Paulo, através de técnicas espectrofotométricas na região do visível.

Os resultados analíticos foram avaliados com base nas legislações federal e estadual paulista. Das amostras analisadas, 91 (15\%) apresentaram teores de pelo menos uma forma do nitrogênio em desacordo com a legislação estadual e $24(4,0 \%)$ apresentaram teores de nitrato em desacordo com a legislação federal.

Apenas o nitrato apresenta valor máximo permissível na legislação federal, enquanto que a estadual contempla os quatro compostos nitrogenados. Com base nos resultados da presença significativa desses derivados nas amostras analisadas, os quais comprometem a qualidade das águas e apresentam riscos potenciais à saúde humana, sugere-se a sua inclusão na legislação federal.

Composto de nitrogênio. Águas subterrâneas. Análise da água. Código de águas.

Correspondência para / Correspondence to: Janete Alaburda - Av. Dr. Arnaldo, 355 - Cerqueira César - 01246-902 São Paulo, SP - Brasil. Fax (011) 853-3505

Edição subvencionada pela FAPESP (Processo nº 97/09815-2).

Recebido em 16.6.1997. Reapresentado em 2.10.1997. Aprovado em 20.10.1997. 


\begin{abstract}
Introduction

Nitrogen compounds in drinking waters have been related to groundwater contamination and inadequate sanitary conditions. Nitrite and nitrate are etiologic agents of methemoglobinemia. In acid solution, nitrous acid formed from nitrite can react with secondary amines to form carcinogenic nitrosamines. The survey of ammoniacal and albuminoid nitrogen, nitrite and nitrate in groundwater supplies as regards the extent of the contamination they cause and discussion of the drinking water regulation regarding nitrogen compounds.

Material and Method

Samples collected predominantly in the Metropolitan Region of S. Paulo City was analysed for nitro gen compounds using colorimetric methods: $\mathrm{N}-\mathrm{NH} 3$ and $\mathrm{N}$-albuminoid by the Nessler method, nitrite by diazoted sulfanilamide with $\mathrm{N}$ (1-naphthyl)-ethylenediamine, and nitrate by reaction with phenoldisulphonic acid.

Results Federal and S. Paulo State drinking water regulations, respectively, Portaria $36 / 90$ and Decreto $n^{\circ} 12.486$, were applied to interpret the results obtained. Of the 607 samples analysed, 15\% of them had at least one of the concentrations of nitrog en compounds exceeding the maximum contaminant level (MCL) of the S. Paulo State Regulation. Otherwise, as regards the Federal Regulation, only $4 \%$ of the samples exceeded the MCL requirement for nitrate.

Conclusion In federal drinking water regulation only MCL for nitrate is reported. Otherwise, S. Paulo State regulation requirements report MCLs for all the compounds that have been analysed in this work. The observed results showed that concentrations of ammonia and albuminoid nitrogen, and nitrite, as well as nitrate, gave rise to water of inadequate quality, further they may have adverse effects on human health. The inclusion of nitrogen compounds other than nitrate in federal regulation is recommended.
\end{abstract}

Nitrogen compounds. Ground-waters. Water analysis. Water.

\section{INTRO DUÇÃO}

Dentre as substâncias que podem constituir risco para a saúde humana, incluem-se os compostos de nitrogênio nos seus diferentes estados de oxidação: nitrogênio amoniacal e albuminóide, nitrito e nitrato.

A amônia pode estar presente naturalmente em águas superficiais ou subterrâneas, sendo que usualmente sua concentração é bastante baixa devido à sua fácil adsorção por partículas do solo ou à oxidação a nitrito e nitrato. Entretanto, a ocorrência de concentrações elevadas pode ser resultante de fontes de poluição próximas, bem como da redução de nitrato por bactérias ou por íons ferrosos presentes no solo $3,7,19$. A presença da amônia produz efeito significativo no processo de desinfecção da água pelo cloro, através da formação de cloraminas, que possuem baixo poder bactericida ${ }^{3}$.

O nitrato é um dos íons mais encontrados em águas naturais, geralmente ocorrendo em baixos te- ores nas águas superficiais, mas podendo atingir altas concentrações em águas profundas ${ }^{1}$. O seu consumo através das águas de abastecimento está associado a dois efeitos adversos à saúde $2,4,12,15$ : a indução à metemoglobinemia, especialmente em crianças, e a formação potencial de nitrosaminas e nitrosamidas carcinogênicas.

O desenvolvimento da metemoglobinemia a partir do nitrato nas águas potáveis depende da sua conversão bacterial para nitrito durante a digestão, o que pode ocorrer na saliva e no trato gastrointestinal2,12,15. As crianças pequenas, principalmente as menores de 3 meses de idade, são bastante susceptíveis ao desenvolvimento desta doença devido às condições mais alcalinas do seu sistema gastrointestinal ${ }^{13}$, fato também observado em pessoas adultas ${ }^{4}$ que apresentam gastroenterites, anemia, porções do estômago cirurgicamente removidas e mulheres grávidas.

O nitrito, quando presente na água de consumo humano, tem um efeito mais rápido e pronunciado do que o nitrato. Se o nitrito for ingerido diretamen- 
te, pode ocasionar metemoglobinemia independente da faixa etária do consumidor ${ }^{3}$.

As nitrosaminas e nitrosamidas podem surgir como produtos de reação entre o nitrito ingerido ou formado pela redução bacteriana do nitrato, com as aminas secundárias ou terciárias e amidas presentes nos alimentos. O pH ótimo para a reação de nitrosaminação é entre 2,5 a 3,5, faixa semelhante à encontrada no estômago humano após a ingestão de alimentos $^{2}$. Tanto as nitrosaminas como as nitrosamidas estão relacionadas com o aparecimento de tumores em animais de laboratório ${ }^{4}$.

O aumento da contaminação das águas por compostos nitrogenados vem merecendo atenção especial, uma vez que está se tornando um problema mundial, devido a sua ampla e diversificada procedência ${ }^{4,11,12,17}$. No Brasil, as águas subterrâneas constituem uma fonte importante de abastecimento, sendo que no Estado de São Paulo mais de 20.000 poços profundos e uma quantidade imensurável de poços escavados rasos fornecem águas para abastecimento público, uso industrial e irrigação?.

A legislação federal vigente ${ }^{5}$ (Portaria 36/90) não estabelece limites para as concentrações de nitrogênio amoniacal, nitrogênio albuminóide e nitrito, porém devido aos efeitos adversos à saúde causados pelos compostos nitrogenados, considera-se importante a inclusão desses compostos, tal como já contemplado nas Normas Técnicas Especiais (NTA) 60 do Decreto Estadual no $12.486^{18}$. O objetivo do presente trabalho é obter dados referentes à ocorrência de compostos nitrogenados em aquíferos subterrâneos utilizados como fonte de abastecimento.

\section{MATERIAL E MÉTO DO}

Foram analisadas 607 amostras de água provenientes de poços localizados predominantemente na Região
Metropolitana da Grande São Paulo, no período de dezembro/94 a janeiro/97. As amostras foram colhidas e transportadas ao laboratório por técnicos especialmente treinados para a execução do presente estudo, seguindose as recomendações da "American Public Health Associations"'.

Os métodos utilizados para as determinações espectrofotométricas de nitrogênio amoniacal e albuminóide, nitrito e nitrato são os adotados pelo Instituto Adolfo Lutz ${ }^{10}$, apresentados resumidamente na Tabela 1. Para as medidas óticas foi utilizado um espectrofotômetro marca Hach modelo DR 2.000.

\section{RESU LTAD O $S$}

Na Tabela 2 estão apresentados os valores dos limites máximos de derivados de nitrogênio permissíveis nos padrões de potabilidade da legislação estadual paulista, referente a poços, e da legislação federal, sendo que esses foram utilizados como parâmetros para a avaliação das amostras analisadas.

As Tabelas 3 e 4 apresentam o número total de análises de água cujo teor de nitrogênio, em seus diferentes estados de oxidação, têm valores superiores aos permitidos pelo Decreto Estadual 12.486 e pela Portaria 36/90, respectivamente.

Das 607 amostras de águas analisadas, 91 (15\%) apresentaram teores de pelo menos uma forma de nitrogênio acima do limite permissível pela legislação estadual paulista. Dessas amostras condenadas, 44 não atenderam à legislação devido apenas ao elevado teor de nitrogênio, o que corresponde a 7,3\% do total de amostras analisadas, enquanto as 47 amostras restantes, além dos teores de nitrogênio, também apresentaram outros parâmetros físico-químicos em desacordo com essa legislação.

Considerando a Portaria Federal, das 607 amostras analisadas somente $24(4,0 \%)$ apresentaram teores de nitrato em desacordo com essa legislação.

Tabela 1 - Descrição resumida da metodologia utilizada para análise de nitrogênio amoniacal e albuminóide, nitrito e nitrato.

Table 1 - Summary of methodology employed for analysis of nitrate, nitrite, ammonia and albuminoid nitrogen compounds.

\begin{tabular}{lllc}
\hline Parâmetro & \multicolumn{1}{c}{ Método* } & $\begin{array}{c}\text { Comprim. } \\
\text { de onda }\end{array}$ & $\begin{array}{c}\text { Precisão** } \\
\mathrm{mg} / \mathrm{L}\end{array}$ \\
\hline Nitr. amoniacal & Destilação; reagente de Nessler & $425 \mathrm{~nm}$ & $\pm 0,02$ \\
Nitr. albuminóide & $\begin{array}{l}\text { Oxidação com permanganato alcalino, } \\
\text { destilação, reagente de Nessler } \\
\text { Reação de diazotação com sulfanilamida }\end{array}$ & $425 \mathrm{~nm}$ & $\pm 0,02$ \\
Nitrito & $\begin{array}{l}\text { e N-1-naftil-etilenodiamina } \\
\text { Nitrato }\end{array}$ & $520 \mathrm{~nm}$ & $\pm 0,001$ \\
& $\begin{array}{l}\text { Evaporação da amostra, reação com ácido } \\
\text { fenoldissulfônico, neutralização com } \\
\text { hidróxido de sódio }\end{array}$ & $400 \mathrm{~nm}$ & $\pm 0,05$ \\
\hline
\end{tabular}

* Instituto Adolfo Lutz ${ }^{10}$ (1985).

** Resultados obtidos a partir da validação dos métodos analíticos no laboratório da Seção de Águas do Instituto Adolfo Lutz. 
Tabela 2 - Valores máximos permissíveis na legislação para teores de nitrogênio em águas destinadas para o consumo humano.

Table 2 - Maximum contaminant levels for nitrogen compounds allowed in Brazilian drinking water regulations.

\begin{tabular}{lcc}
\hline Derivado do nitrogênio & Legislação estadual paulista* & Legislação federal** \\
\hline Nitr. amoniacal (mg N/L) & 0,05 & - \\
Nitr. albuminóide(mgN/L) & 0,08 & - \\
Nitrito (mg N/L) & 0,02 & - \\
Nitrato (mg N/L) & 6,0 & 10 \\
\hline
\end{tabular}

* Decreto 12.486 , de $20 / 10 / 78^{18}$

** Portaria 36/G M de 19.1.1990

Tabela 3 - Número de amostras de águas de poços localizados na Região M etropolitana da Grande São Paulo com teores de nitrogênio acima do limite previsto na legislação estadual paulista.

Table 3 - Well water samples from M etropolitan Region of S. Paulo City with concentrations of nitrogen compounds above maximum contaminant levels foresean in S. Paulo state regulations.

\begin{tabular}{|c|c|c|c|c|c|c|c|}
\hline \multicolumn{2}{|c|}{ [Nitr. amoniacal] } & \multicolumn{2}{|c|}{ [N itr. albuminóide] } & \multicolumn{2}{|c|}{ [N itrito] } & \multicolumn{2}{|c|}{ [N itrato] } \\
\hline $\begin{array}{l}\geq 0,05 \\
\mathrm{mg} \mathrm{N} / \mathrm{L}\end{array}$ & $\%$ amostras & $\begin{array}{l}\geq 0,08 \\
\mathrm{mg} \mathrm{N} / \mathrm{L}\end{array}$ & $\%$ amostras & $\begin{array}{l}\geq 0,02 \\
\mathrm{mg} \mathrm{N} / \mathrm{L}\end{array}$ & $\%$ amostras & $\begin{array}{l}\geq 6,0 \\
\mathrm{mg} \mathrm{N} / \mathrm{L}\end{array}$ & \%amostras \\
\hline 54 & 8,9 & 24 & 4,0 & 22 & 3,6 & 46 & 7,6 \\
\hline
\end{tabular}

Tabela 4 - Número de amostras de águas de poços localizados na Região M etropolitana da Grande São Paulo com teores de nitrogênio acima do limite previsto na legislação federal.

Table 4 - Well water samples from Metropolitan Region of S. Paulo City with concentrations of nitrogen compounds above maximum contaminant levels foresean in federal regulation.

\begin{tabular}{|c|c|c|c|c|c|c|c|}
\hline \multicolumn{2}{|c|}{ [N amoniacal] } & \multicolumn{2}{|c|}{ [N albuminóide] } & \multicolumn{2}{|c|}{ [N itrito] } & \multicolumn{2}{|c|}{ [Nitrato $]$} \\
\hline $\begin{array}{l}\geq 0,05 \\
\mathrm{mg} \mathrm{N} / \mathrm{L}\end{array}$ & $\%$ amostras & $\begin{array}{l}\geq 0,08 \\
\mathrm{mg} \mathrm{N} / \mathrm{L}\end{array}$ & $\%$ amostras & $\begin{array}{l}\geq 0,02 \\
\mathrm{mg} \mathrm{N} / \mathrm{L}\end{array}$ & $\%$ amostras & $\begin{array}{l}\geq 10 \\
\mathrm{mg} \mathrm{N} / \mathrm{L}\end{array}$ & $\%$ amostras \\
\hline - & - & - & - & - & - & 24 & 4,0 \\
\hline
\end{tabular}

\section{DISCUSSÃO E CONCLUSÕES}

A avaliação dos resultados foi feita com base nos padrões de potabilidade estabelecidos na legislação federal e na legislação estadual paulista, sendo que esta última estabelece limites diferenciados de acordo com a procedência da água: águas de abastecimento público e águas de consumo particular, subdividida em: águas de poços e águas de fontes. Ambas as legislações apresentam as concentrações dos compostos de nitrogênio expressas em relação ao seu equivalente em nitrogênio.

Seguindo-se a Portaria Federal, com relação aos compostos de nitrogênio, apenas o nitrato é incluído com um teor máximo permissível de $10 \mathrm{mgN}-\mathrm{NO}_{3} /$ L, que é idêntico ao limite tolerado pelo decreto estadual em águas de abastecimento, sendo que este valor foi adotado especificamente para proteger crianças da metemoglobinemia. Com base neste limite, somente $4 \%$ das amostras apresentariam risco à saúde (Tabela 4).

Dos conteúdos dos demais compostos de nitrogênio, avaliados nas águas de poços, constatou-se a presença de $8,9 \%, 4,0 \%$ e $3,6 \%$, respectivamente, de nitrogênio amoniacal, nitrogênio albuminóide e nitrito acima dos limites permissíveis no Decreto Estadual (Tabela 3). A diferença entre as percentagens encontradas ocorre porque nem sempre os quatro compostos de nitrogênio analisados estão presentes simultaneamente numa mesma amostra, devido à origem da água e da fonte de contaminação. Portanto, a ausência de nitrato não significa que amônio e nitrito estejam ausentes. Ainda com base na legislação estadual paulista, seriam 7,6\% as amostras de águas com teor de nitrato acima do limite tolerado, uma vez que esta legislação estabelece como limite máximo o valor de $6 \mathrm{mg} \mathrm{N}-\mathrm{NO}_{3} / \mathrm{L}$.

Alguns autores ${ }^{4,8}$ consideram que concentrações superiores a $3 \mathrm{mg} \mathrm{N}-\mathrm{NO}_{3} / \mathrm{L}$ são indicativos de contaminação devido às atividades antropogênicas. No presente trabalho, das 607 amostras analisadas 64 $(10,5 \%)$ apresentaram concentrações de nitrato superiores a esse limite, sendo importante o monitoramento dessas águas por um determinado período, visando a tomada de ações preventivas.

Nas águas tratadas e cloradas utilizadas para consumo, praticamente só é esperado encontrar teores de nitrato devido às condições oxidantes desse meio. Porém, no caso das pequenas e médias populações urbanas e comunidades rurais, as águas subterrâneas 
empregadas como fontes alternativas de abastecimento são utilizadas diretamente, sem nenhum tratamento prévio. Nesses casos, torna-se importante detectar as quatro espécies nitrogenadas para se avaliar corretamente a qualidade da água, principalmente porque o nitrito, nitrogênio amoniacal e nitrogênio albuminóide são indicadores de contaminação do aquífero e de possíveis condições higiênico-sanitárias insatisfatórias.

A presença de concentrações de nitrogênio amoniacal e de nitrogênio albuminóide podem estar relacionadas com as construções precárias dos poços e a falta de proteção do aquífero, sendo que o conhecimento dos seus teores permite adotar atitudes corretivas rápidas, evitando-se que a contaminação se transforme num problema crônico e irreversível, e possibilita a orientação quanto à necessidade de um tratamento prévio da água.

O limite de $10 \mathrm{mg} \mathrm{N}-\mathrm{NO}_{3} / \mathrm{L}$ foi estabelecido a partir de estudos sobre a ocorrência de metemoglobinemia em crianças que consumiam águas de poços ${ }^{4}$, sendo que existem relatos de ocorrência da doença originadas pela ingestão de águas com conteúdos de nitrato inferiores a esse valor $^{12}$. Por outro lado, existem estudos ${ }^{14,16}$ que relacionam a ingestão de elevado teor de nitrato com o aumento de certos tipos de câncer, porém mais investigações estão sendo realizadas e os efeitos carcinogênicos dos derivados de nitrogênio ainda não foram considerados no estabelecimento dos limites permissíveis previstos na legislação referente às águas para consumo humano.

A literatura referente aos estudos sobre a avaliação de compostos de nitrogênio em águas de poços no Brasil é muito precária, bem como a divulgação de estudos epidemiológicos com respeito a metemoglobinemia e a ocorrência do desenvolvimento de alguns tipos de câncer, devido à ingestão de teores elevados de nitrato, são praticamente inexistentes. Fernícola (1989) considera "que dada a pouca informação sobre casos de metemoglobinemia nas Américas, cabe indagar se isto é devido à baixa incidência da doença ou à falta de notificação".

A legislação federal refere-se somente ao nitrato, não fazendo nenhuma ressalva aos demais compostos de nitrogênio, os quais são bem caracterizados na legislação estadual paulista referentes às águas de poços e fontes, que são consideradas como águas sem nenhum tratamento prévio e, portanto, susceptíveis à presença de compostos prejudiciais à saúde. A Portaria 36/90 de abrangência nacional, apesar de não especificar claramente no seu texto, destina-se às águas de abastecimento tratadas, ignorando ou desconsiderando o uso de fontes alternativas sem tratamento prévio, fato muito comum no Brasil.

No Estado de São Paulo as águas subterrâneas são utilizadas para diversas finalidades dentre as quais tem-se: uso industrial, abastecimento particular e de condomínios, e também abastecimento público. Desta forma, torna-se importante à detecção dos derivados do nitrogênio para orientação quanto à necessidade de um tratamento prévio da água e para levantamentos epidemiológicos em relação à metemoglobinemia e ao desenvolvimento de alguns tipos de câncer.

Com base no levantamento realizado, verifica-se que a contaminação das águas subterrâneas por compostos de nitrogênio é significativa, sugerindo-se monitoramentos dessas águas para viabilizar uma rediscussão da legislação federal.

\section{REFERÊN CIAS}

1. AMERICAN PUBLIC HEALTH ASSOCIATION (APHA). Standard methods for the examination of water and wastewater. $17^{\mathrm{a}} \mathrm{ed}$. Washington, 1992. p.4-75/ 4-93.

2. AMERICAN WATER WORKS ASSOCIATION (AWWA). Water quality and treatment: a handbook of community water supplies. $4^{\mathrm{a}}$ ed. New York, McGraw Hill, 1990.

3. BATALHA, B.H.L. \& PARLATORE, A.C. Controle da qualidade da água para consumo humano: bases conceituais e operacionais. São Paulo, CETESB, 1993.
4. BOUCHARD, D.C.; WILLIANS, M.K.; SURAMPALLI, R.Y. Nitrate contamination of ground water: sources and po-tencial health effects. J. Am. Water Works Ass., 84: 85-90,1992.

5. BRASIL. Leis Decretos, etc. Portaria $\mathrm{n}^{\circ} 36$, de 19.01.90; O Ministério da Saúde aprova normas e padrões de potabilidade de água destinada ao consumo humano. Diário Oficial, Brasília, 23 jan. 1990, Seção 1. p. 1651-1654.

6. FERNÍCOLA, N.G.J. Metaemoglobinemia infantil causada por nitratos. Bol. Sanit. Panamer., 106, 32-40, 1985. 
7. FORMAGGIA, D.M.E.; PERRONE, M.A.; MARINHO, M.J.F.; SOUZA, R.M.G.L. Portaria 36 GM de 19/01/90 Necessidade de Revisão. Eng. Sanit. Amb., 1(2): 5-10, 1996.

8. FOSTER, S. \& HIRATA, R. Determinação do risco de contaminação das águas subterrâneas. São Paulo, Instituto Geológico, 1993.

9. HIRATA, R.C.A.; BASTOS, C.R.A.; ROCHA, G.A.; GOMES, D.C.; IRITANI, M.A. Groundwater pollution risk and vulnerability map of the São Paulo State. In: Congresso Brasileiro de Águas Subterrâneas, $6^{\circ}$. Porto Alegre. Anais, Porto Alegre, ABAS, 1990. p. 236-46.

10. INSTITUTO ADOLFO LUTZ. Normas analíticas do Instituto Adolfo Lutz. $3^{\mathrm{a}}$ ed. São Paulo, IMESP, 1985. V.1, p. 313-9. Métodos químicos e físicos para a análise de alimentos.

11. MACLEAF, P.R. \& SCHOEDER, E.D. Denitrification using a membrane-immobolized biofilm. J. W. Works Ass., 87: 7786, 1995.

12. MATO, A. P. Determinação de nitratos, nitritos e prováveis fontes de contaminação em águas de poços e sua influência na metemoglobinemia infantil. São Paulo, 1996. [Dissertação de Mestrado - Curso de Pós-Graduação em Saneamen-to Ambiental, Universidade Mackenzie].
13. OLIVEIRA, J.J.V; VALLILO, M.I.; PEDRO, N.A.R.; ZENEBON, O. Estudo comparativo de métodos para determinação de nitrato em águas naturais. Rev. Inst. Adolfo Lutz, 47: 25-30, 1987

14. OLMOS, R.P. \& ECLEVENIA, J. Elementos traza en leches de lactamia españolas III - determinación de nitratos. Alimentaria, Madrid, 142: 51-7, 1983.

15. ORGANIZAÇÃO MUNDIAL DA SAÚDE. Nitratos, nitritos and N-nitroso compounds. Geneva, 1978.

16. RADEMACHER, J.J.; YOUNG, T.B.; KANAREK, M.S Gastric cancer mortality and nitrate levels in Wisconsin drinking water. Archiv. Environ. Health, 47: 292-4, 1992.

17. ROVIRA, R.F. \& CANOVES, A.F. Nitratos, aspectos bromatológicos, toxicológicos e analíticos. Alimentaria, Madrid, 24: 15-21, 1988.

18. SÃO PAULO (Estado), Decreto no 12.486, de 20.10.78 NTA 60 Águas de consumo alimentar. In: Legislação: água para o consumo humano, potabilidade, fluoretação. São Paulo, CETESB, 1994. p.51-2.

19. SOCIETY FOR WATER TREATMENT AND EXAMINATION. Water treatment and examination. $4^{\mathrm{a}} \mathrm{ed} . \mathrm{J}$ \&A Churchill, London 1970. p. 133-5. 